\title{
Some aspects of perceptual coding of duration in visual duration discrimination*
}

\author{
LORRAINE G. ALLAN, A. B. KRISTOFFERSON, and MARNIE E. RICE† \\ McMaster University, Hamilton, Ontario, Canada
}

\begin{abstract}
Data are presented which indicate two major differences between duration discrimination performance and discrimination performance usually observed in other psychophysical tasks. A decrement in duration discrimination performance with increasing temporal delays between the presentation of two successive stimuli was not found, and the usual difference in level of performance between forced-choice and single-stimulus lasks was not observed. The time-order error in duration discrimination is also discussed.
\end{abstract}

It is well established that in many psychophysical discrimination tasks involving the sequential presentation on the same trial of the two stimuli to be compared, the temporal interval between the two stimuli is an important variable, discriminability decreasing as the interval is lengthened. For example, Kinchla and Smyzer (1967) and Tanner (1961) have shown this effect for loudness discrimination, Bull and Cuddy (1972) and Moss, Myers, and Filmore (1970) for pitch discrimination, Kinchla and Allan $(1969,1970)$ for visual movement discrimination, and Allan (1968) for spatial position. A number of quantitative memory models to account for decreased discriminability with increasing interstimulus interval (ISI) have been proposed (Kinchla \& Allan. 1969; Massaro, 1970; Wickelgren, 1969).

In a study which required the $\mathrm{O}$ to make comparative judgments about the duration of two brief stimulus events. Small and Campbell (1962) did not observe the same phenomenon. Their stimuli were filled auditory intervals. On each trial, two duration stimuli were presented sequentially, and the $O$ was required to indicate which was the longer (or the shorter). They found that duration discrimination performance did not change for ISIs of $5,200,800$, and $3,200 \mathrm{msec}$ for duration stimuli in the $400-\mathrm{msec}$ range. As stimulus duration was shortened (40-, 4-, and .4-msec ranges), the shorter values of ISI ( 5 and $200 \mathrm{msec}$ ) resulted in a decrement in discriminability relative to the fairly constant discriminability level at the longer values.

The absence of a decrement in discriminability with increasing ISI is important in the development of theory concerned with the psychophysics of brief time intervals. The absence of an ISI effect would indicate

*This research was supported by Grants A8260 and A7919 from the National Research Council of Canada. Aspects of these experiments are reported in a bachelors thesis by Marnie $\mathfrak{E}$. Rice (née $\mathrm{McKee}$ ). The thesis is available as McMaster Technical Report No.42, McKee, Allan, \& Kristofferson, Duration discrimination of brief visual off-flashes, 1970.

$\div$ Now at York University, Toronto, Ontario, Canada. that a model for duration discrimination would have to differ in some fundamental aspect from existing psychophysical models concerned with the sequential presentation of the stimuli to be compared. Given our interest in the development of a model for duration discrimination (Allan, Kristofferson. \& Wiens, 1971: Carbotte \& Kristofferson, 1971; Kristofferson, 1973; Kristofferson \& Allan, 1973), we thought it necessary to investigate carefully the relationship between duration discrimination performance and ISI. In the Small and Campbell study, relatively few observations were collected from each $\mathrm{O}$ under each experimental condition, and only the data averaged over Os are available. The experiments to be reported in this paper examine the effect of variations in ISI on duration discrimination performance for brief durations. To increase the generality of the results, a visual stimulus was used to mark the duration to be judged.

The two-alternative forced-choice (FC) task is one method of presenting two sequential stimuli for comparison. The FC discrimination task involves the sequential presentation on each trial of two stimuli, $\mathrm{S}_{0}$ and $S_{1}$, which differ along the same dimension, and the requirement that the $O$ make a comparative judgment about their magnitudes. On some trials, $S_{0}$ is presented first, followed by $S_{1}$; on the remaining trials, $S_{1}$ is followed by $S_{0}$. Green and Swets (1966) have presented data from a number of psychophysical studies which clearly indicate that discrimination performance in a FC task is superior to that in a single-stimulus (SS) task. A SS discrimination task involves the presentation of one stimulus on each trial and the requirement that the $O$ make a judgment about the magnitude of that stimulus. Since knowledge about the relationship between FC and SS duration discrimination performance is essential to a theoretical treatment of the psychophysics of brief time intervals, the experiments to be reported were also designed to provide such information. Specifically, when the $O$ is asked to compare two duration stimuli. $S_{0}$ and $S_{1}$, is his performance better in the case when the two stimuli are presented on the same trial than in the case when only one stimulus is presented on each trial? 

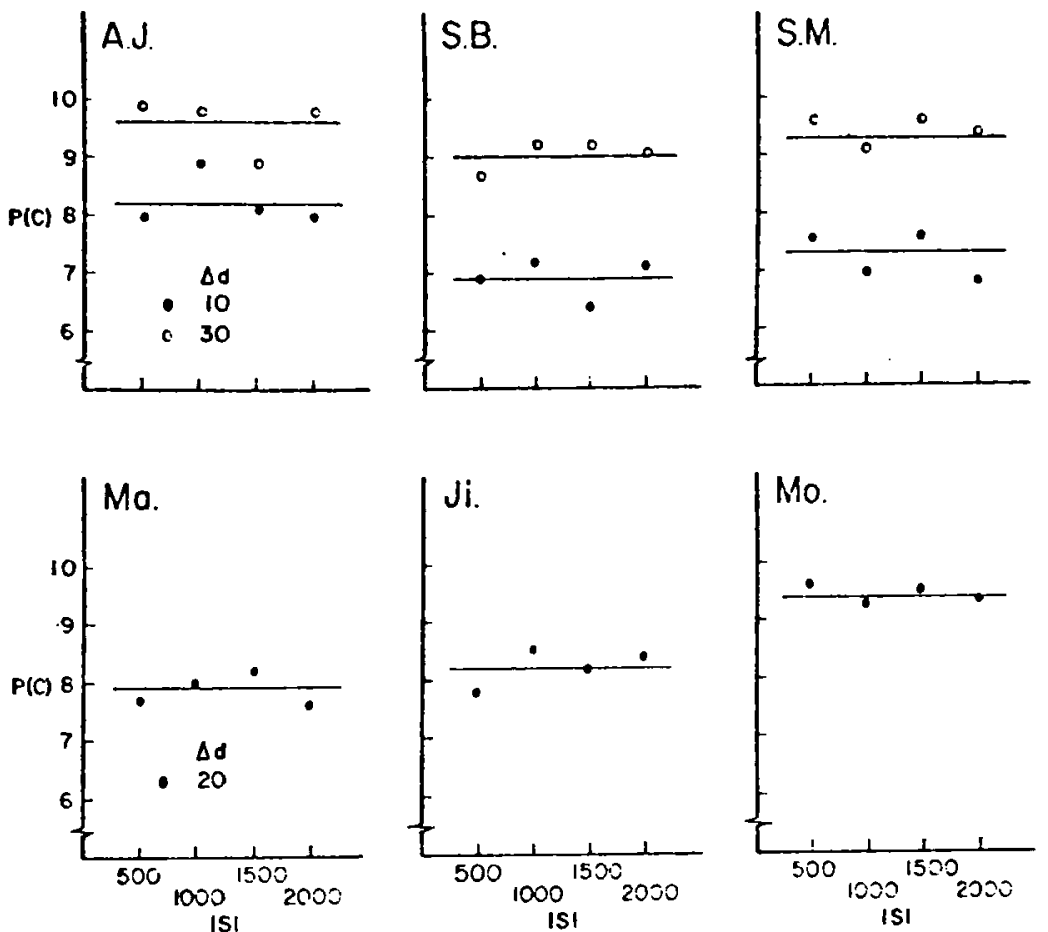

ISI
Fig. 1. P(C) as a function of ISI for each $O$ in Experiment I. The line indicates the 0 's mean performance over the four values of ISI for a given value of $\Delta d$.

\section{EXPERIMENT I}

\section{Method}

Six paid Os participated in this experiment. Each $O$ sat in an IAC sound-attenuated, dimly illuminated, auditory chamber, approximately $66 \mathrm{~cm}$ from the visual display. The visual display consisted of a glow modulator bulb (Sylvania R 1131C) driven by an Iconix power supply (Model 6195-4). The bulb was enclosed in a metal box with an aperture, $4 \mathrm{~mm}$ in diam, subtending a visual angle of $21 \mathrm{~min}$. The aperture was covered on the inside with a Kodak No. 96 neutral density 2.00 filter and then translucent milk glass. The luminance of the display was $50 \mathrm{fL}$ (150 UB Photo Research photometer). Clearly audible warning signals and feedback information were provided through a speaker in each chamber. The presentation and timing of the signals and the recording of the responses were under the control of a PDP-8/S computer.

For three Os (A.J., S.B., and S.M.), the visual display was illuminated at all times except when a duration stimulus was being presented. The stimulus was a dark period, or "dark flash." For the other three Os ( $\mathrm{Ma}, \mathrm{Ji}$, and $\mathrm{Mo}$ ), the visual display was off at all times except when the duration stimulus was presented. The stimulus was a "light flash." The two-alternative forced-choice paradigm (FC) was used. Each trial consisted of the presentation of two sequential duration stimuli. In each block of trials, on half the trials the longer stimulus was presented first, followed by the shorter stimulus (an $S, S_{0}$ stimulus pattern); on the remaining trials, the shorter was first, followed by the longer (an $S_{0} S_{1}$ stimulus pattern). The order of presentation of the two stimulus patterns was determined randomly. Four values of ISI were used, 500, 1,000, 1,500, and 2,000 msec.

Each trial began with a 1 -sec auditory warning signal, followed $200 \mathrm{msec}$ later by an $S_{1} S_{0}$ or an $S_{0} S_{1}$ stimulus pattern. The $O$ was then given $2.5 \mathrm{sec}$ to indicate his response by pushing one of two buttons on the arm of his chair. He was instructed to decide whether the first duration was the longer (an $R_{1}$ 。 response) or whether the second was the longer (an $R_{0}$, response). On $S_{1} S_{0}$ trials, a 100 -msec auditory signal was presented at the end of the response period. No signal was presented on $S_{0} S_{1}$ trials. The next trial began $1.1 \mathrm{sec}$ after the end of the response period with the onset of the $1-\mathrm{sec}$ auditory warning signal.

For the dark-flash Os, the duration of the short stimulus $\left(d_{0}\right)$ was 50 msec. The duration of the long stimulus $\left(d_{1}\right)$ was equal to $\mathrm{d}_{0}+\Delta \mathrm{d}$, where $\Delta \mathrm{d}$ was 10 or $30 \mathrm{msec}$. Thus, there were eight experimental conditions (two values of $\Delta d$ and four values of ISI). For the light-flash $O s, d_{0}$ was $100 \mathrm{msec}$ and $\Delta d$ was $20 \mathrm{msec}$, resulting in four experimental conditions.

Each session consisted of five blocks of 100 trials each, with a 1 -min rest interval between blocks. During a session, $\Delta d$ and ISI were constant. Each $O$ ran two sessions under each of the experimental conditions, with the restriction that each condition be used once before any condition was repeated. The first 100 trials in each session were not included in the data analysis.

\section{Results and Discussion}

For each $O$ and each condition, $P\left(R_{10} i S_{1} S_{0}\right)$, $P\left(R_{10} \mid S_{0} S_{1}\right)$, and $P(C)$ are presented in Table 1 , where

$$
P(C)=1 / 2\left[P\left(R_{10} \mid S_{1} S_{0}\right)-P\left(R_{10} \mid S_{0} S_{1}\right)+1\right]
$$

Each value of $P(C)$ is based on 800 observations. In Fig. $1, P(C)$ is shown as a function of ISI. The line represents the $O$ 's mean performance over the four values of ISI for a given value of $\Delta d$. The data very clearly indicate that discrimination performance does not decrease with increasing values of ISI for either dark flashes or light flashes. The data from both the dark flash and the light flash duration discrimination tasks are in agreement with the auditory data from Small and Campbell (1962). Variations in ISI from 500 to $2,000 \mathrm{msec}$ do not result in a decrement in discrimination performance.

One possible explanation of the absence of a 
decrement in discriminability with increasing ISI is that the $O$ actually ignores one of the stimuli on each trial. Variations in ISI would therefore be an ineffective variable. It has often been suggested in the literature (for example, Harris, 1952; Bull \& Cuddy, 1972) that a "roving-standard" design increases the likelihood that the $\mathrm{O}$ makes a comparative judgment on each trial. The roving-standard design applied to the $\mathrm{FC}$ duration discrimination paradigm means that during any block of trials more than one value of $d_{0}$ is used and the $O$ is uncertain as to which $\mathrm{d}_{0}$ will occur on each trial. Recently, Carbotte (1972) has examined the relationship between duration discrimination performance and ISI, making use of the roving-standard design. Two empty intervals bounded by $10 \cdot \mathrm{msec} 2,000-\mathrm{Hz}$ pulses were presented on each trial. Six values of ISI $(0,125,250$, $500,1,000$, and $2,000 \mathrm{msec}$ ), four values of $\mathrm{d}_{0}$, ranging between 115 and $250 \mathrm{msec}$, and one value of $\Delta d$ were used. During a session, ISI was constant and $\mathrm{d}_{0}$ was varied, the four values occurring with equal frequency in each block of trials. Carbotte's results are similar to those of Small and Campbell (1962). Variations in ISI from 500 to $2.000 \mathrm{msec}$ had little effect on performance. For ISIs less than $500 \mathrm{msec}$, performance is disrupted relative to the fairly constant level for ISIs greater than $500 \mathrm{msec}$.

It appears that the processing of duration information differs in some fundamental way from the processing of sensory information (for example, amplitude, pitch, movement, position). Lengthening the temporal interval between two duration stimuli which are to be compared does not produce a decrement in discriminability. This is the case for dark flashes, light flashes, empty auditory intervals, and filled auditory intervals. Manipulation of ISI over the same range of values does produce a decrement in other psychophysical discrimination tasks.

A number of duration discrimination studies (e.g., Blakely, 1933; Stott, 1933, 1935; Woodrow, 1951) have reported that for durations briefer than a critical value, $\mathrm{d}_{\mathrm{c}}, \mathrm{P}\left(\mathrm{R}_{10} \mid \mathrm{S}_{1} \mathrm{~S}_{0}\right)>\mathrm{P}\left(\mathrm{R}_{01}: \mathrm{S}_{0} \mathrm{~S}_{1}\right)$, the difference between the two conditional probabilities decreasing as the stimulus durations approach $d_{c}$. where $d_{c}$ is referred to as the time-order indifference duration. For durations longer than $\mathrm{d}_{\mathrm{c}}$, the difference is in the opposite direction, $P\left(R_{01}\right.$ i $\left.S_{0} S_{1}\right)>P\left(R_{10} \mid S_{1} S_{0}\right)$. the difference becoming larger as the stimulus durations increase. The difference in the magnitude of the two conditional probabilities is referred to as the time-order error, and the usual interpretation is that for durations briefer than $d_{c}$, the duration of the second stimulus is underestimated, resulting in larger values of $P\left(R_{10} \mid S_{1} S_{0}\right)$ than of $P\left(R_{01} \mid S_{0} S_{1}\right)$. For durations longer than $d_{c}$, the duration of the second member is overestimated, resulting in larger values of $P\left(R_{01}, S_{0} S_{1}\right)$ than of $P\left(R_{10}: S_{1} S_{0}\right)$. The exact value of $d_{c}$ varies widely over studies, and an explanation of the transition of underestimation to overestimation is lacking.

It should be noted that in duration discrimination.
Table 1

Probabilities Summarizing Each Observer's Performance Under Each of the Experimental Conditions: Experiment I

\begin{tabular}{|c|c|c|c|c|c|c|}
\hline 0 & $\mathrm{~d}_{\mathrm{o}}$ & $\Delta d$ & ISI & $\begin{array}{l}P\left(R_{1} 0^{\prime}\right. \\
\left.S_{1} S_{0}\right)\end{array}$ & $\begin{array}{c}P\left(R_{1}\right. \\
\left.S_{0} S_{1}\right) \\
\end{array}$ & $P(C)$ \\
\hline \multirow[t]{2}{*}{ A J. } & 50 & 10 & $\begin{array}{r}500 \\
1000 \\
1500 \\
2000\end{array}$ & $\begin{array}{l}.817 \\
.771 \\
.844 \\
.794\end{array}$ & $\begin{array}{l}.228 \\
.194 \\
.225 \\
.192\end{array}$ & $\begin{array}{l}.797 \\
.888 \\
.812 \\
.800\end{array}$ \\
\hline & & 30 & $\begin{array}{r}500 \\
1000 \\
1500 \\
2000\end{array}$ & $\begin{array}{l}.995 \\
.993 \\
.993 \\
.990\end{array}$ & $\begin{array}{l}.013 \\
.017 \\
.020 \\
.023\end{array}$ & $\begin{array}{l}.991 \\
.983 \\
.887 \\
.984\end{array}$ \\
\hline \multirow[t]{2}{*}{ S.B. } & 50 & 10 & $\begin{array}{r}500 \\
1000 \\
1500 \\
2000\end{array}$ & $\begin{array}{l}.698 \\
.706 \\
.561 \\
.613\end{array}$ & $\begin{array}{l}.310 \\
.267 \\
.279 \\
.197\end{array}$ & $\begin{array}{l}.694 \\
.718 \\
.645 \\
.707\end{array}$ \\
\hline & & 30 & $\begin{array}{r}500 \\
1000 \\
1500 \\
2000\end{array}$ & $\begin{array}{l}.932 \\
.917 \\
.898 \\
.890\end{array}$ & $\begin{array}{l}.202 \\
.080 \\
.062 \\
.041\end{array}$ & $\begin{array}{l}.866 \\
.919 \\
.919 \\
.914\end{array}$ \\
\hline \multirow[t]{2}{*}{ S.M. } & 50 & 10 & $\begin{array}{r}500 \\
1000 \\
1500 \\
2000\end{array}$ & $\begin{array}{l}.755 \\
.724 \\
.798 \\
.751\end{array}$ & $\begin{array}{l}.225 \\
.324 \\
.273 \\
.401\end{array}$ & $\begin{array}{l}.765 \\
.702 \\
.765 \\
.680\end{array}$ \\
\hline & & 30 & $\begin{array}{r}500 \\
1000 \\
1500 \\
2000\end{array}$ & $\begin{array}{l}.963 \\
.935 \\
.965 \\
.948\end{array}$ & $\begin{array}{l}.041 \\
.117 \\
.042 \\
.067\end{array}$ & $\begin{array}{l}.961 \\
.910 \\
.962 \\
.941\end{array}$ \\
\hline Ma. & 100 & 20 & $\begin{array}{r}500 \\
1000 \\
1500 \\
2000\end{array}$ & $\begin{array}{l}.781 \\
.789 \\
.807 \\
.770\end{array}$ & $\begin{array}{l}.240 \\
.189 \\
.173 \\
.241\end{array}$ & $\begin{array}{l}.770 \\
.800 \\
.817 \\
.764\end{array}$ \\
\hline Ji. & 100 & 20 & $\begin{array}{r}500 \\
1000 \\
1500 \\
2000\end{array}$ & $\begin{array}{l}.692 \\
.877 \\
.828 \\
.834\end{array}$ & $\begin{array}{l}.123 \\
.170 \\
.186 \\
.151\end{array}$ & $\begin{array}{l}.784 \\
.854 \\
.821 \\
.842\end{array}$ \\
\hline Mo. & 100 & 20 & $\begin{array}{r}500 \\
1000 \\
1500 \\
2000 \\
\end{array}$ & $\begin{array}{l}.965 \\
.915 \\
.945 \\
.942 \\
\end{array}$ & $\begin{array}{l}.053 \\
.056 \\
.053 \\
.063 \\
\end{array}$ & $\begin{array}{r}.956 \\
.930 \\
.946 \\
.940 \\
\end{array}$ \\
\hline
\end{tabular}

interest has been in the relationship between stimulus duration and the relative size of the two conditional probabilities. In other discrimination tasks (for example brightness, amplitude, weight), interest has been in the relationship between ISI and the relative size of the two conditional probabilities. It has often been found that $P\left(R_{01} \mid S_{0} S_{1}\right)>P\left(R_{10} \mid S_{1} S_{0}\right)$, the difference increasing as ISI is increased (Woodworth \& Schlosberg. 1954).

In "signal detection" language. the interpretation of the time-order error in duration discrimination by Blakely and Stott is a "sensory" one. A response preference explanation is just as plausible. Specifically, it could be argued that the $\mathrm{O}$ has a preference for making a $R_{10}$ response at short durations. and that this preference decreases as stimulus duration increases. Kinchla and Allan (1969) and Kinchla and Smyzer (1967) provide detailed discussions about the response preference view of the time-order error in amplitude and movement discrimination. 
Table 2

Probabilities Summarizing Each Observer's Performance Under Each of the 10 Conditions in the Single-Stimulus Task: Experiment II

\begin{tabular}{|c|c|c|c|c|c|}
\hline 0 & $\mathrm{~d}_{0}$ & $\Delta d$ & $P\left(R_{1} \mid S_{1}\right)$ & $P\left(R_{1} \mid S_{0}\right)$ & $P(C)$ \\
\hline \multirow[t]{2}{*}{ R.M. } & 50 & $\begin{array}{l}10 \\
20 \\
30 \\
40 \\
50\end{array}$ & $\begin{array}{l}.737 \\
.790 \\
.884 \\
.930 \\
.958\end{array}$ & $\begin{array}{l}.349 \\
.254 \\
.156 \\
.075 \\
.036\end{array}$ & $\begin{array}{l}.696 \\
.768 \\
.864 \\
.928 \\
.961\end{array}$ \\
\hline & 100 & $\begin{array}{l}10 \\
20 \\
30 \\
40 \\
50\end{array}$ & $\begin{array}{l}.689 \\
.802 \\
.913 \\
.928 \\
.973\end{array}$ & $\begin{array}{l}.472 \\
.390 \\
.270 \\
.161 \\
.128\end{array}$ & $\begin{array}{l}.611 \\
.712 \\
.822 \\
.884 \\
.923\end{array}$ \\
\hline \multirow[t]{2}{*}{ S.M. } & 50 & $\begin{array}{l}10 \\
20 \\
30 \\
40 \\
50\end{array}$ & $\begin{array}{l}.679 \\
.939 \\
.935 \\
.980 \\
.983\end{array}$ & $\begin{array}{l}.272 \\
.092 \\
.090 \\
.013 \\
.031\end{array}$ & $\begin{array}{l}.704 \\
.924 \\
.923 \\
.984 \\
.976\end{array}$ \\
\hline & 100 & $\begin{array}{l}10 \\
20 \\
30 \\
40 \\
50\end{array}$ & $\begin{array}{l}.583 \\
.698 \\
.885 \\
.908 \\
.968\end{array}$ & $\begin{array}{l}.413 \\
.281 \\
.184 \\
.096 \\
.061\end{array}$ & $\begin{array}{l}.585 \\
.695 \\
.851 \\
.901 \\
.954\end{array}$ \\
\hline \multirow[t]{2}{*}{ L.B. } & 50 & $\begin{array}{l}10 \\
20 \\
30 \\
40 \\
50\end{array}$ & $\begin{array}{l}.768 \\
.879 \\
.960 \\
.965 \\
.990\end{array}$ & $\begin{array}{l}.326 \\
.147 \\
.071 \\
.025 \\
.018\end{array}$ & $\begin{array}{l}.721 \\
.866 \\
.945 \\
.970 \\
.986\end{array}$ \\
\hline & 100 & $\begin{array}{l}10 \\
20 \\
30 \\
40 \\
50\end{array}$ & $\begin{array}{l}.583 \\
.736 \\
.845 \\
.854 \\
.915\end{array}$ & $\begin{array}{l}.454 \\
.430 \\
.241 \\
.215 \\
.173\end{array}$ & $\begin{array}{l}.565 \\
.654 \\
.802 \\
.804 \\
.871\end{array}$ \\
\hline
\end{tabular}

Examination of the appropriate conditional probabilities tabulated in Table 1 indicates that for four of the six Os $P\left(R_{10} \mid S_{1} S_{0}\right)$ and $P\left(R_{0_{1}} \mid S_{0} S_{1}\right)$ are about equal for any experimental condition. In general, $P\left(R_{01} \mid S_{0} S_{1}\right)>P\left(R_{10} \mid S_{1} S_{0}\right)$ for S.B., while the opposite is true for S.M. A sensory interpretation of the time-order error would have difficulty incorporating these results. A response preference interpretation would not.

\section{EXPERIMENT II}

\section{Method}

Six Os participated in this experiment, three of whom (A.J., S.B., and S.M.) participated in Experiment I. Three performed the FC task, three the SS task. The duration stimuli were dark flashes.

For the FC task, the trial structure was identical to that described in Experiment I. ISI was constant at $500 \mathrm{msec}$.

In the SS task, each trial began with a 1 -sec auditory warning signal, followed $200 \mathrm{msec}$ later by an $S_{1}$ stimulus or an $S_{0}$ stimulus, the two stimuli occurring with equal frequency in each block of trials. The $\mathrm{O}$ was then given $2.5 \mathrm{sec}$ to indicate his response, long $\left(R_{1}\right)$ or short $\left(R_{0}\right)$. On $S_{1}$ trials, a 100-msec auditory signal was presented at the end of the response period. The next trial began $1.1 \mathrm{sec}$ after the end of the response period.

Two values of $d_{0}(50$ and $100 \mathrm{msec})$ and five values of $\Delta d$ $(10,20,30,40$, and $50 \mathrm{msec})$ were used. During a session, $d_{0}$ and $\Delta \mathrm{d}$ were constant. Each session consisted of five blocks of 100 trials. Each $O$ ran three sessions on each of the 10 combinations of $d_{0}$ and $\Delta d$, with the restriction that each combination be used an equal number of times before any of the 10 was repeated. Data from the first cycle and from the first block of trials were not included in the data analy sis.

\section{Results and Discussion}

For each $\mathrm{O}$ in the SS task, $\mathrm{P}\left(\mathrm{R}_{1} \mid \mathrm{S}_{1}\right) . \mathrm{P}\left(\mathrm{R}_{1} \mid \mathrm{S}_{0}\right)$, and $P(C)$ are shown for each condition in Table 2. Similarly, for each $O$ in the FC task, $P\left(R_{10} \mid S_{1} S_{0}\right)$, $P\left(R_{10} \mid S_{0} S_{1}\right)$, and $P(C)$ are shown in Table 3 . In both tables, each value of $P(C)$ is based on 800 observations. In Fig. 2, performance averaged over the three Os in the SS task and over the three Os in the FC task is presented as a function of $\Delta \mathrm{d}$. On the average, there is little difference in performance between the two tasks.

The absence of a difference in discriminability between the FC and SS tasks could merely be a result of using two groups of three different Os. However, Carbotte (1972), using empty auditory intervals and two $\mathrm{d}_{0}$ values, 150 and $250 \mathrm{msec}$, found no systematic differences in discriminability between the two tasks when the same three Os were tested under both tasks.

Examination of Table 3 reveals that in general

Table 3

Probabilities Summarizing Each Observer's Performance Under Each of the 10 Conditions in the Forced-Choice Task: Experiment II

\begin{tabular}{|c|c|c|c|c|c|}
\hline $\mathrm{O}$ & $\mathrm{d}_{0}$ & $\Delta \mathrm{d}$ & $P\left(R_{1}, ! S_{1} S_{0}\right)$ & $P\left(R_{10} \mid S_{0} S_{1}\right)$ & $P(C)$ \\
\hline \multirow[t]{2}{*}{ A.J. } & 50 & $\begin{array}{l}10 \\
20 \\
30 \\
40 \\
50\end{array}$ & $\begin{array}{r}.838 \\
.958 \\
.988 \\
.988 \\
1.000\end{array}$ & $\begin{array}{l}.191 \\
.041 \\
.010 \\
.010 \\
.010\end{array}$ & $\begin{array}{l}.824 \\
.959 \\
.989 \\
.989 \\
.996\end{array}$ \\
\hline & 100 & $\begin{array}{l}10 \\
20 \\
30 \\
40 \\
50\end{array}$ & $\begin{array}{l}.580 \\
.761 \\
.903 \\
.962 \\
.998\end{array}$ & $\begin{array}{l}.370 \\
.199 \\
.082 \\
.035 \\
.016\end{array}$ & $\begin{array}{l}.605 \\
.781 \\
.911 \\
.964 \\
.991\end{array}$ \\
\hline \multirow[t]{2}{*}{ S.B. } & 50 & $\begin{array}{l}10 \\
20 \\
30 \\
40 \\
50\end{array}$ & $\begin{array}{l}.681 \\
.835 \\
.922 \\
.894 \\
.960\end{array}$ & $\begin{array}{l}.252 \\
.245 \\
.110 \\
.096 \\
.029\end{array}$ & $\begin{array}{l}.736 \\
.796 \\
.906 \\
.899 \\
.966\end{array}$ \\
\hline & 100 & $\begin{array}{l}10 \\
20 \\
30 \\
40 \\
50\end{array}$ & $\begin{array}{l}.539 \\
.684 \\
.804 \\
.814 \\
.863\end{array}$ & $\begin{array}{l}.349 \\
.208 \\
.209 \\
.171 \\
.135\end{array}$ & $\begin{array}{l}.595 \\
.731 \\
.798 \\
.821 \\
.865\end{array}$ \\
\hline \multirow[t]{2}{*}{ P.H. } & 50 & $\begin{array}{l}10 \\
20 \\
30 \\
40 \\
50\end{array}$ & $\begin{array}{l}.655 \\
.852 \\
.829 \\
.922 \\
.920\end{array}$ & $\begin{array}{l}.180 \\
.119 \\
.121 \\
.080 \\
.052\end{array}$ & $\begin{array}{l}.738 \\
.867 \\
.855 \\
.921 \\
.935\end{array}$ \\
\hline & 100 & $\begin{array}{l}10 \\
20 \\
30 \\
40 \\
50\end{array}$ & $\begin{array}{l}.561 \\
.682 \\
.721 \\
.820 \\
.772\end{array}$ & $\begin{array}{l}.346 \\
.328 \\
.216 \\
.121 \\
.127\end{array}$ & $\begin{array}{l}.608 \\
.676 \\
.752 \\
.848 \\
.822\end{array}$ \\
\hline
\end{tabular}


$P\left(R_{10} \mid S_{1} S_{0}\right)$ and $P\left(R_{01} \mid S_{0} S_{1}\right)$ are quite similar for any experimental condition.

It is clear from Tables 2 and 3 that, for both the FC task and the SS task, performance for $\AA_{0}=50 \mathrm{msec}$ is considerably better than performance for $\mathrm{d}_{0}=$ $100 \mathrm{msec}$. We have reported previously (Allan et al, 1971) that for light flashes discriminability often was not influenced by a change in $\mathrm{d}_{0}$ from 50 to $100 \mathrm{msec}$. Recently, we (Kristofferson, 1973) have presented data which begin to resolve this apparent contradiction. Results from duration discrimination tasks using light flashes and empty auditory intervals appear to support the hypothesis that discriminability is constant for changes in $d_{0}$ over certain ranges of $d_{0}$, but changes between ranges. An elaboration of the model for duration discrimination developed in Allan et al (1971) is also discussed in Kristofferson (1973).

\section{CONCLUDING COMMENTS}

In this paper, we have presented evidence that indicates two major differences between duration discrimination performance and discrimination performance usually observed in other psychophysical tasks. A decrease in performance was not found with increasing temporal delays between the presentation of two successive stimuli, and the usual difference in level of performance between FC and SS tasks was not observed.

Decision theory discrimination models, when applied to the FC paradigm, usually assume that the $O$ compares the internal representations of the two stimuli presented on each trial (Green \& Swets, 1966). This results in two equal-variance distributions of differences, one representing the possible differences on $S_{1} S_{0}$ trials, the other on $S_{0} S_{1}$ trials. The $O$ is represented as adopting a criterion difference, and if the observed difference exceeds the criterion as making an $R_{10}$ response. Such a model predicts better FC than SS performance.

Kristofferson and Allan (1972) and Allan and
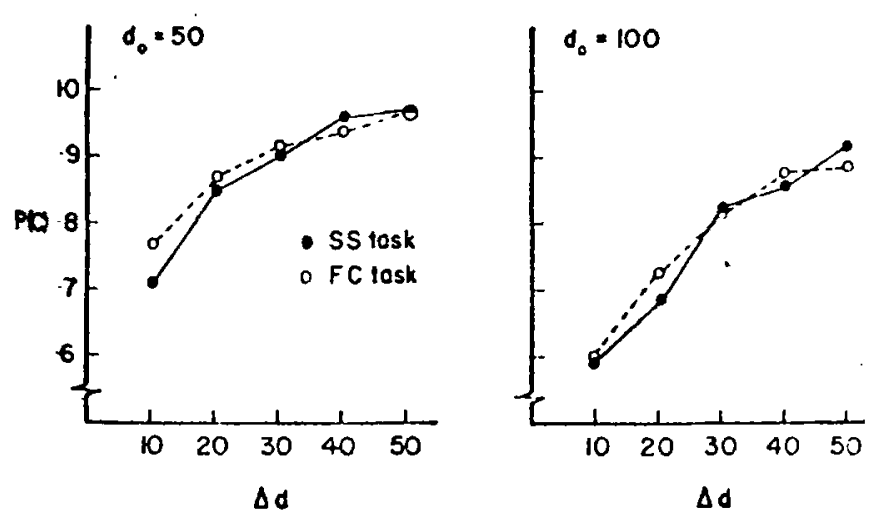

Fig. 2. $P(C)$ as a function of $\Delta d$ in Experiment $I 1$.
Kristofferson (in press) discussed an alternative decision process for the FC paradigm. They suggested that the $O$ adopts a criterion value of the internal dimension, and makes an independent decision after each stimulus presentation. His response on each trial is then based on these two decisions. Such a decision process yields the prediction that, for a fixed criterion, SS and FC psychometric functions should be identical. Furthermore, it could be argued that if the $O$ were making a decision after each stimulus, the time between the two stimuli (ISI) would be unimportant, as long as the $O$ had enough time to make his decision. Thus, qualitatively, a decision theory model incorporating the response comparison decision process would account for the major results of the experiments reported in this paper.

\section{REFERENCES}

Allan, L. G. Visual position discrimination: A model relating temporal and spatial factors. Perception \& Psychophysics, 1968, 4, 267-278.

Allan, L. G., \& Kristofferson, A. B. Successiveness discrimination: Two models. Perception \& Psychophysics, $1974,15,37-46$.

Allan, L. G., Kristotterson, A. B., \& Wiens, E. W. Duration discrimination of brief light flashes. Perception \& Psychophysics, 1971, 9, 327-334.

Blakely, W. A. The discrimination of short empty temporal intervals. Unpublished doctoral dissertation, University of Illinois, 1933.

Bull, A. R., \& Cuddy, L. L. Recognition memory for pitch of fixed and roving stimulus tones. Perception \& Psychophysics, $1972,11,105-109$.

Carbotte, R. M. Discrimination of brief empty time intervals. Unpublished doctoral dissertation, McMaster University, 1972.

Carbotte, R. M., \& Kristofferson, A. B. Discrimination of brief empty time intervals. Technical Report No. 21, Department of Psychology, McMaster University, 1971.

Green, D. M., \& Swets, J. A. Signal detection theory and psychophysics. New York: Wiley, 1966.

Harris, J. D. The decline of pitch discrimination with time. Journal of Experimental Psychology, 1952, 43, 96-99.

Kinchla, R. A., \& Allan, L. G. A theory of visual movement perception. Psychological Review, 1969, 76, 537-558.

Kinchla, R. A., \& Allan, L. G. Visual movement perception: A comparison of sensitivity to vertical and horizontal movement. Perception \& Psychophysics, 1970, 8, 399-405.

Kinchla, R. A., \& Smyzer, F. A. A diffusion model of perceptual memory. Perception \& Psychophysics, 1967, 2, 219-229.

Kristofferson, A. B. Psychological timing mechanisms. A paper presented at the fourth annual meeting of the Lake Ontario Vision Establishment, Niagara Falls, Ontario, 1973.

Kristofferson, A. B., \& Allan, L. G. Successiveness and duration discrimination. In S. Kornblum (Ed.), Attention and performance IV. New York: Academic Press, 1973. Pp. 737-749.

Massaro, D. Perceptual processes and forgetting in memory tasks. Psychological Review, 1970, 77, 557-567.

Moss, S. M., Myers, J. L., \& Filmore, T. Short-term recognition memory of tones. Perception \& Psychophysics, 1970. 7. 369-373.

Small, A. M., \& Campbell, R. A. Temporal differential sensitivity 
for auditory stimuli. American Journal of Psychology, 1962, $75,401-410$.

Stott, L. H. The discrimination of short tonal durations. Unpublished doctoral dissertation, University of Illinois, 1933.

Stott, L. H. Time-order errors in the discrimination of short tonal durations. Journal of Experimental Psychology, 1935, 18, 741-766.

Tanner, W. P. Physiological implications of psychophysical data. Annals of the New York Academy of Sciences, 1961, 89, 752-765. Reprinted in J. A. Swets (Ed.), Signal detection and recognition by human observers: Contemporary readings. New York: Wilev, 1964. Pp. 351-365.
Wickelgren, W. A. Associative strength theory of recognition memory for pitch. Journal of Mathematical Psychology, 1969, $6,13-61$.

Woodrow, H. Time perception. In S. S. Stevens (Ed.), Handbook of experimental psychology. New York: Wiley, 1951. Chapter 32.

Woodworth, R. S., \& Schlosberg, H. Expermental psychology'. New York: Holt, 1954.

(Received for publication June 13, 1973; accepted August 10, 1973.) 